\title{
ANALYSIS AND ROUTING OF BASIC PARAMETERS OF TASUJ EARTHQUAKE (APRIL 2013, NORTHWEST OF IRAN) WITH AN EMPHASIS ON GEODETIC DATA, FORESHOCKS AND LARGE AFTERSHOCKS
}

\author{
A. SAKET ${ }^{a}, *$, S.M FATEMI AGHDA ${ }^{\text {a }}$, H. SADEGHI ${ }^{\text {b }}$, A. FAHIMIFAR ${ }^{\text {c }}$ \\ $a^{a^{*}}$ Faculty of Earth Sciences, Kharazmi University, Tehran, Iran, E-mail: *Alisaketgeo@gmail.com, Fatemi@khu.ac.ir \\ ${ }^{\mathrm{b}}$ Department of Geology, Faculty of Science, Ferdowsi University of Mashhad, Mashhad, Iran, E-mail: Sadeghi@Um.ac.ir \\ ${ }^{\mathrm{c}}$ Faculty of Civil Engineering and Environment, Amir Kabir University, Tehran, Iran, E-mail: Fahim@ aut.ac.ir
}

Received: 25.06.2021 / Accepted: 22.07.2021 / Revised: 05.08.2021 / Available online: 15.12.2021

DOI: 10.2478/jaes-2021-0020

KEY WORDS: Seismic quiescence, Statistical Parameters, Aftershock, Foreshock, Geodetic data, Focal depth

\begin{abstract}
In the science of seismology, issues such as the study of tectonic seismic maps and the identification of the behavioural pattern of pre-earthquakes and aftershocks are among the cases that have been proposed as the basis of applied geological studies in recent decades. Accordingly, numerous studies and researches in this field have been carried out in different regions of the world. However, the results of these studies so far have not been able to meet the needs of this field in a practical and practical way, and in this regard, there is a need to provide practical approaches in this field. In order to realize this approach, there is a need for specialized research and case studies in this field in order to be able to present studies on earthquake risk reduction in an institutionalized and practical way by identifying practical patterns. In this study, the basis of the case study, considering the special characteristics of Tasuj earthquake as one of the important earthquakes according to the basic patterns that can be provided in this field for this earthquake has been considered. Also geodetic analysis of Tasuj fault and the other faults studied for estimation of accuracy this analysis for prediction of earthquake. The results of this study indicate that the fault causing the Tasuj earthquake, contrary to what is presented in the fault map of the region and previous reports and articles, is of the strike-slip type, which should be corrected. Also, the analysis of the behavioural pattern of geodetic data, foreshocks and aftershocks as a precursor shows that these patterns can be used in predicting major earthquakes and large aftershocks. To predict the time of large aftershocks in this study, three phases have been used, which are based on changes in depth to magnitude, changes in seismic quiescence to magnitude and depth changes.
\end{abstract}

\section{INTRODUCTION}

Tasuj earthquake occurred on April $2013\left(\mathrm{M}_{\mathrm{b}}=5.2\right)$ six months after the doublet 2012 Varzaghan earthquake that took place with corresponding magnitudes of 6.4 and 6.3 in an approximate $150 \mathrm{~km}$ radial distance from the center of that. According to the report of Institute of Geophysics University of Tehran, the focal depth of Tasuj was $8 \mathrm{~km}$ from the ground surface. This earthquake $\left(\mathrm{M}_{\mathrm{b}}=5.2\right)$ occurred in a zone without any instrumental seismic event recorded (with $\mathrm{M}>5.0$ ) in an area with $50 \mathrm{~km}$ radius around it. The reason for consideration this radius was to identify the earthquakes caused by faults around of epicenter. The occurrence of Tasuj earthquake, as well as activity of the fault responsible for it indicate the necessity for a detailed study on epicenter of this earthquake, which was recorded near Tasuj in Shabestar city (Figure 1). Tasuj earthquake was felt in Tabriz (100 km east of epicenter), Marand (35 km northeast of epicenter), Bonab (100 km southeast of epicenter), and Shabestar (40 km east of epicenter). This evidence shows that the main released wave in this earthquake had an eastward direction. Considering the geological conditions and characteristics of the buildings in this area, no serious life and property losses was caused by this seismic event.

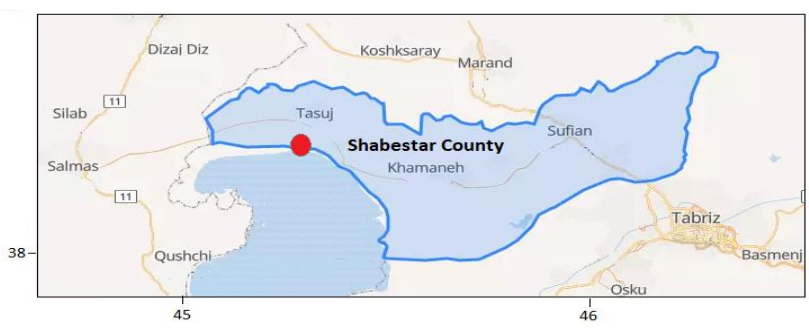

Figure 1. Map of the epicentre and surrounding cities

Considering the main emphasis of this paper on statistical evaluation of seismicity parameters for Tasuj earthquake, the seismicity parameters have been introduced in this part.

\subsection{Previous knowledge of seismicity parameters}

These parameters, which are discussed in the present work, include the seismicity history, main earthquake (focal depth and focal mechanism), foreshocks, and aftershocks. The literature review of the associated works revealed that studies in this field were initiated in countries with high seismicity such as the United States and Japan on latest 19 century. The first specialized study about aftershocks was conducted by Omori (1894). Omori conducted a comprehensive study on the 
aftershocks of the world's major earthquakes. The result of his research led to the presentation of a formula for reducing the number of aftershocks by distance from the time of the main earthquake. Kanto earthquake (1923, Japan) in the beginning of 20 century is among the important seismic events for which a comprehensive seismic study was conducted (Bolt, 1999). Study of important seismicity parameters of California earthquake (1952, USA) in the middle of twentieth century with highlighting its aftershocks and foreshocks by Richter (1955) is one of the most exhaustive seismological studies.

In this study, Richter for the first time entered a new phase of scientific analysis of pre-earthquakes and aftershocks of an earthquake. Tajima and Kanamori (1985) conducted another work on the global distribution of aftershocks and the detection of suitable patterns for them. Researchers such as Mendoza and Hartzell (1988) presented a key research on aftershocks and their relationship to the movement of main faults. The results of these researchers showed that the aftershocks of different earthquakes spread near the surface epicenter of the main earthquake and along the rupture caused by its fault. Das and Henry (2003) conducted another work on the spatial relationship between the main earthquake and largest aftershocks and their distributions. The results of these researchers indicated that there is a clear relationship between the type of fault and the magnitude of aftershocks. In addition to the mentioned cases, Zhao et al. (2011) studied the aftershocks' positioning of 2008 Sichuan earthquake in China. Nishimora et al. (2011) performed a similar study on aftershocks of March 2011 earthquake in the East Coast of Honshu of Japan $(\mathrm{Mw}=9.0)$. In these two studies, the behavioral pattern of aftershocks and their distribution were discussed. Tartar and Farahbod (2007) worked on seismicity parameters of Kojour earthquake in north of Iran; Saket et al. (2005) compared seismicity parameters of two earthquakes of Bam and Zarand (both located in Kerman Province, Iran); The results of this study showed that the magnitude of the strongest aftershocks and the distribution of aftershocks have a clear relationship with the type of fault. Nourbakhsh Mirzaei et al. (2002) presented a comprehensive study on basic parameters of Iran's earthquakes. The main objective of the present work is to study seismicity parameters of Tasuj earthquake on the basis of the previous works conducted in the world, as well as presentation of new methods and a model for studying with emphasis on fault type, foreshocks and large aftershocks. Because the study of aftershocks is of great assistance in tectonic detection of the seismic active areas, as well as risk management of large aftershock and the detection of their patterns are very important in seismological aspects. As an example, occurrence of the largest aftershock $(\mathrm{Mw}=7.4)$ after east coast of Japan earthquake in 2011 (with $\mathrm{Mw}=9.0$ ), which resulted in a halfmeter surface displacement and high damage, indicated that sometimes the study of aftershocks is as much important as the main shocks. The importance of large aftershocks is more highlighted because the structures weakened by the main earthquake would be destroyed by the following large aftershocks. In this regard, the analysis of statistical data of aftershocks pursues two main objectives: detection of dangerous aftershocks and better identification of reactivated faults within a quake-stricken area (Zhao et al., 2011).

\subsection{Seismicity and seismotectonic properties of the study area}

As mentioned, the case study of this article focuses on the Tasuj earthquake. Studies on the historical earthquakes show that two earthquake records exist for activities of Tasuj earthquake: January 11,1807 and September 6, 1857, both with Mercalli intensity of 8 (Amberesis and Melville 1981). In addition, the study of teleseismic data records from 1961 to 1990 reveals that the epicenter of the below-mentioned earthquakes are located on Tasuj fault, and they might have occurred due to the movements of this fault (IRSC). Among these earthquakes are 31-12-1963 $\left(\mathrm{M}_{\mathrm{b}}=4.5\right), 24-05-1981\left(\mathrm{M}_{\mathrm{b}}=4.6\right), 29-06-1984\left(\mathrm{M}_{\mathrm{b}}=4.6\right), 10$ 07-1986 $\left(\mathrm{M}_{\mathrm{b}}=4.7\right)$, and 17-07-1986 $\left(\mathrm{M}_{\mathrm{b}}=4.5\right)$, where the two last occurred within less than one week, indicating the occurrence of double earthquakes in this zone. Because they were large in size, location, and focal mechanism. In a slightly larger scale, this phenomenon was also observed in the vicinity of this area (a radius smaller than $150 \mathrm{~km}$ ) in Varzaghan Earthquake (2012). Two earthquakes with moment magnitudes of 6.3 and 6.4, which were among the largest doublet earthquakes of Iran, occurred in the same area with an interval of a few minutes (IRSC).

\subsubsection{Seismicity parameters in Tasuj earthquake 1.3.1.2. Tasuj fault responsible for earthquake}

The occurrence of Tasuj earthquake (April 2013, Mb=5.2) was very important in this area. Regarding the direction of Tasuj fault and its intersection with the main North Tabriz Fault in east of Tasuj fault (Figure 2), there seems to be no distinct relationship between this earthquake and Ahar-Varzaghan Earthquake (2012). However, we cannot neglect the high activity of the fault responsible for Varzaghan earthquake in the occurrence of Tasuj Earthquake, which resulted in tens of aftershocks greater than 4 and lasting for even six months after the main seismic event. The study area is located in north western of East Azerbaijan province. Because of the short distance between the epicenter of the main earthquake and the Tasuj fault, its intersection with north Tabriz fault, as well as its long distance with other active faults and seismotectonic conditions of area, Tasuj fault was identified as the fault responsible for this earthquake. Tasuj fault is a quaternary fault with a curved strike that crosses $5 \mathrm{~km}$ north of Tasuj and Lake Uromia. The western part of this fault has an NE-SW direction dipping toward NE, while its eastern part has a WNW-ESW direction dipping to NNE (Figure 2). The fault has a compressive mechanism and an estimated length of $61 \mathrm{~km}$. According to Pourkermani and Arian (1998), the Upper Red and Hezar-Darreh formations (in the north) are thrusted over the Urmia subsidence (in the south) along this fault. Also, North Tabriz fault is the most important active fault in northwest of Iran, and was responsible for large earthquakes in East Azerbaijan in previous centuries, which destroyed the city of Tabriz several times.

However, the proposed mechanism for Tasuj fault and the west end of north Tabriz fault on the map of major active faults of Iran introduce these faults as dip-slip thrust faults in the location of their intersection. There is a distinct contradiction about the responsible fault since the focal mechanism of this earthquake (Tasuj) was presented as a strike-slip fault (Figure 2), so it is necessary to be corrected on the active fault map. This case is important because the evaluation of risk is different for a strikeslip fault in comparison to a dip-slip fault. This difference can be shown in the rate of seismicity and distribution and magnitude of aftershocks. 


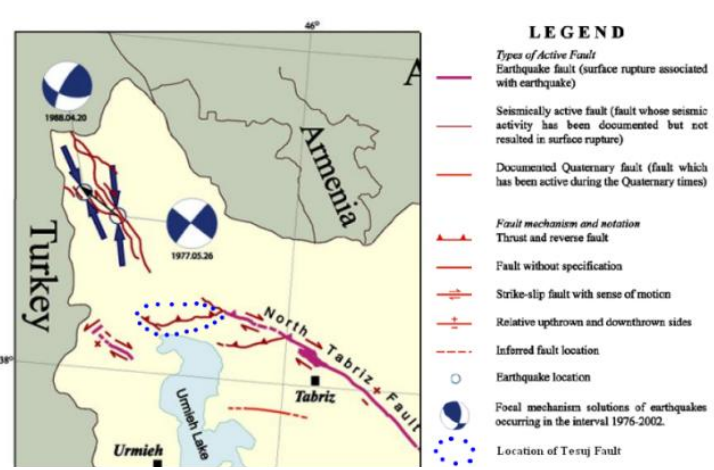

Figure 2. The active faults of Tasuj earthquake (Hesami et al., 2003)

\section{Discussion}

\subsection{Foreshocks of Tasuj Earthquake}

In the last decade, satellite-based geodetic techniques such as Thermal Infrared survey (TIR), Synthetic Aperture Radar (SAR) and Global Positioning System (GPS) have considerably developed and their applications to seismotectonic investigation are now manifold (Tronin, 2010) and (Cenni et al, 2015). Geodetic data before two important earthquakes, the Wenchuan, 2008 in China with $\mathrm{Mw}=8.0$ and Gorka 2015 in Nepal with $\mathrm{Mw}=7.8$ recorded by several various stations in two areas and these data showed certain variations before these two earthquakes ( $\mathrm{Gu}$ and Meng 2011). Therefore, the results of studies in two region suggested that geodetic data can be used as a precursor for earthquake prediction.

In this study, we use a multi temporal Synthetic Aperture Radar Interferometry technique (MT-InSAR) with the small baseline that presented by (Karimzadeh et. Al 2013) for geodetic analysis in north east of Iran and Tasuj fault in Figure 3 InSAR (SBAS) approach to map the velocity field around the Tabriz basin and central section of the NTF, Tasuj Fault and another fault of area using ENVISAT Advanced SAR (ASAR) data acquired between 2003 and 2010. The average distance between GPS stations is about $50 \mathrm{~km}$ (Djamour et al., 2011). The study area is also ideal for the InSAR technique owing to its arid to semiarid climate and thus its sparse vegetation cover.

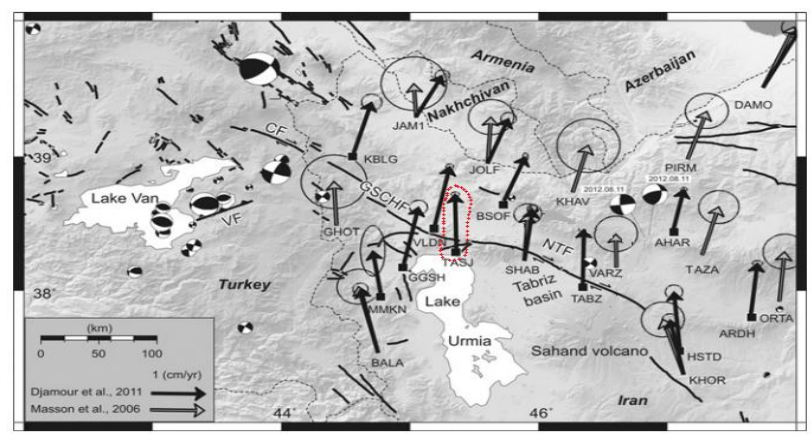

Figure 3. Morphotectonic map of the study area within the Turkish-Iranian plateau

The Figure above (Figure 3) showing active faults (black lines), focal mechanisms and GPS velocity fields relative to Eurasia with $95 \%$ confidence ellipses (with 4 letter site names) on shaded relief from SRTM-3 arc second data. Continuous GPS stations are indicated with black squares at vector tails. Black dashed square shows the frame of the SAR images studied, covering major part of the Tabriz basin and the NTF. GSCHF, Gailatu-Siah Chesmeh-Khoy Fault; VF, Van Fault CF,
Chalderan Fault; NTF, North Tabriz Fault. Vector related to Tasuj Fault is showen with red dashed line on map.

As shown in the center of the map, Tasuj fault until 2011 in a 10 -year period, moved more than $1 \mathrm{~cm}$ annually. Then, in 2013 , the Tasuj earthquake occurred with $M=5.2$. Due to the smaller size of the Tasuj fault and its similar motion to larger faults, the Tasuj earthquake was expected. The Khoy fault in north west of Urmia lake was also the cause of another earthquake with $\mathrm{M}=5.0$ and movement of more than $1 \mathrm{~cm}$ annually with smaller fault size. So If the movement of small fault in a certain period of time is equal to a large fault, there is an expectation of medium and big earthquake on small fault. Because small fault cannot withstand the equivalent stress of large fault. This case can be as a precursor for time of moderate and big earthquake in seismic region. Of course, this claim needs to be confirmed in other parts of the world to prove it.

Two foreshocks with magnitudes of 2.5 and 2.3 occurred nine days and seven hours before the Tasuj earthquake, respectively (Table 1). Information on these foreshocks indicates the descending trend of their foreshock magnitude with the approach of the main shock, implying further energy accumulation for occurrence of the main shock, which is usual before the main shock.

\begin{tabular}{|l|l|l|l|l|l|}
\hline $\begin{array}{l}\text { Origin } \\
\text { Time }\end{array}$ & Lat. & Long. & $\begin{array}{l}\text { Depth } \\
(\mathbf{k m})\end{array}$ & Mag & Ref \\
\hline $2013 / 04 / 04$ & 38.27 & 45.33 & 13.2 & 2.2 & IRSC \\
\hline $2013 / 04 / 09$ & 38.34 & 45.30 & 20 & 2.5 & IRSC \\
\hline $2013 / 04 / 18$ & 38.33 & 45.45 & 16.4 & 2.3 & IRSC \\
\hline
\end{tabular}

Table 1. Statistical parameters of foreshocks and the main shock for Tasuj Earthquake (IRSC)

In this investigation, the available statistical data such as periodical variations of seismicity in the months before main shock studied as a tool for estimating the approximate time of a future important earthquake. As shown in Figure 4, the monthly frequency of seismicity related to Tasuj fault and its neighbouring regions indicates a relative increase and then decrease within a $50 \mathrm{~km}$ radius around the epicentre of main shock. The pattern shown in Figure 4 shows specific two-part behaviour. The first part is the increase in seismicity, which is due to the activation of the region and the formation of discontinuous cracks before the main earthquake, which manifests itself in the form of multiple foreshocks.

In the next step, which prepares the conditions for the occurrence of the main earthquake due to the relative joining of the cracks created along the fault plane due to microearthquakes, we will see the final resistance along the fault to move against the main earthquake. This process is reflected in the reduction in the number of earthquakes, and these conditions are exactly the closest time to the occurrence of the main earthquake, which can vary from a few days to one to two months depending on the tectonic conditions of the region.

However, Figure 4 can be considered confirm this claim. Such behaviour, which was also observed in other earthquakes such as Varzaghan (2012) in northwest $(\mathrm{Mw}=6.4)$, Kaki (2013) in southwest (Mw=6.3), Mourmoori (2013) in west $(\mathrm{Mw}=6.2)$, Goharan earthquake (2013) with $\mathrm{Mw}=6.2$ in southern and Sephid Sang (2017) with $\mathrm{Mw}=6.1$ in northeast of Iran and some other important earthquakes, can be considered as an important 
precursor in the prediction of occurrence of main earthquakes. Therefore, the evaluation of seismotectonic pattern of the different areas in smaller parts of tectonic structural units can be used for presentation of suitable patterns of the prediction of main earthquakes based on foreshocks.

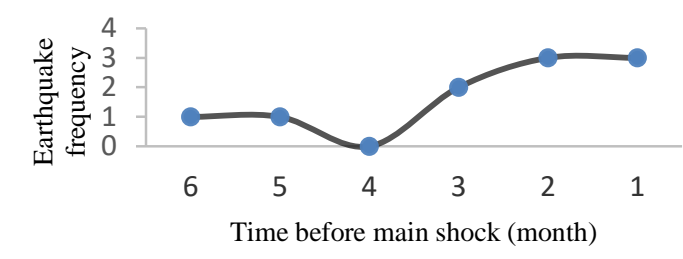

Figure 4. Seismicity variations within a $50 \mathrm{~km}$ radius around the focus of the main shock in Tasuj earthquake (from 6 months before the main shock)

\section{2-2- Aftershocks of Tasuj earthquake}

For Tasuj earthquake, the largest aftershock $\left(M_{b}=4.1\right)$ occurred five minutes after the main shock, followed by 9 aftershocks happened with $\mathrm{M} \geq 3$ within 24 hours after the main shock (Table 2). Considering the fact that the number of aftershocks with $\mathrm{M} \geq 3$ does not exceed 10within the first month after the main shock and these aftershocks have a maximum frequency in the first day after the main shock in the quake-stricken area. This evidence shows the most stress releases within the first day after the main shock. In the following, distribution of aftershocks, location of main shock, and two foreshocks of the Tasuj earthquake are presented in Figure 5.

\begin{tabular}{|c|c|c|c|c|}
\hline $\begin{array}{c}\text { Date, Time } \\
\text { (UTC) }\end{array}$ & Latitude & longitude & Depth & Magnitude \\
\hline $\begin{array}{c}2013 / 04 / 18, \\
10: 39\end{array}$ & $38.32 \mathrm{~N}$ & $45.36 \mathrm{E}$ & 8 & 5.2 \\
\hline $\begin{array}{c}2013 / 04 / 18, \\
10: 44\end{array}$ & $38.39 \mathrm{~N}$ & $45.36 \mathrm{E}$ & 12 & 4.1 \\
\hline $\begin{array}{c}2013 / 04 / 18, \\
10: 53\end{array}$ & $38.41 \mathrm{~N}$ & $45.35 \mathrm{E}$ & 12 & 3 \\
\hline $\begin{array}{c}2013 / 04 / 18, \\
10: 58\end{array}$ & $38.40 \mathrm{~N}$ & $45.36 \mathrm{E}$ & 18 & 3.3 \\
\hline $\begin{array}{c}2013 / 04 / 18, \\
11: 01\end{array}$ & $38.38 \mathrm{~N}$ & $45.38 \mathrm{E}$ & 12 & 3 \\
\hline $\begin{array}{c}2013 / 04 / 18, \\
11: 08\end{array}$ & $38.40 \mathrm{~N}$ & $45.35 \mathrm{E}$ & 14 & 3.1 \\
\hline $\begin{array}{c}2013 / 04 / 18, \\
11: 09\end{array}$ & $38.37 \mathrm{~N}$ & $45.37 \mathrm{E}$ & 15 & 3.2 \\
\hline $\begin{array}{c}2013 / 04 / 18, \\
11: 12\end{array}$ & $38.39 \mathrm{~N}$ & $45.38 \mathrm{E}$ & 14 & 3.4 \\
\hline $\begin{array}{c}2013 / 04 / 18, \\
11: 20\end{array}$ & $38.37 \mathrm{~N}$ & $45.34 \mathrm{E}$ & 16 & 3.8 \\
\hline $\begin{array}{c}2013 / 04 / 18, \\
11: 39\end{array}$ & $38.41 \mathrm{~N}$ & $45.33 \mathrm{E}$ & 12 & 3.9 \\
\hline
\end{tabular}

Table 2. Statistical parameters of main shock and aftershocks with $\mathrm{M} \geq 3$ of Tasuj Earthquake (IRSC)

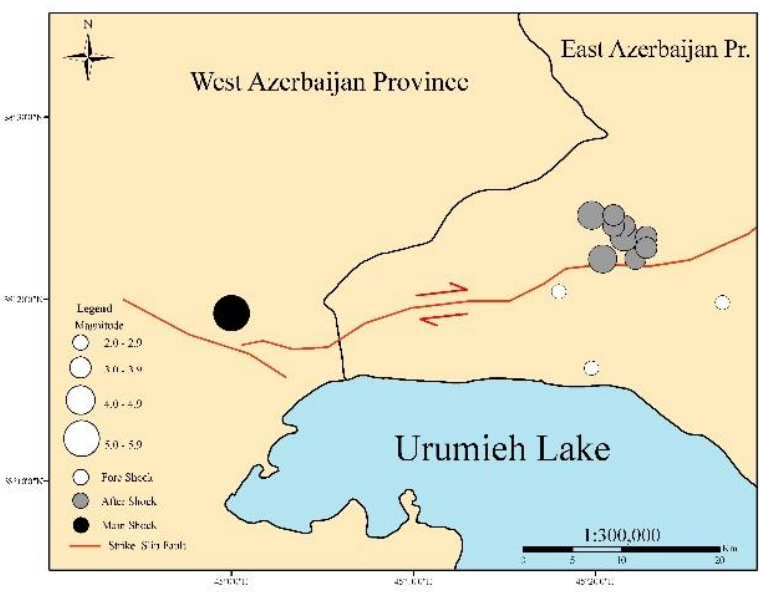

Figure 5. Distribution of foreshocks, main shock, and aftershocks of Tasuj earthquake

\section{2-2-1 Risk Analysis of aftershocks}

Study of large aftershocks in the world suggests that earthquakes with reverse and trust responsible faults are usually followed by larger aftershocks (Saket and Fatemi Aghda, 2009) and (Doss and Henry, 2003) and which was also reported for earthquakes such as kaki (2013) and Murmoori (2014) in south western and western of Iran, respectively (NDRI, 2015). These earthquakes have reverse responsible fault and are followed by big aftershocks. In contrast, aftershocks of earthquakes with strike-slip and normal responsible faults usually occur in small magnitude, including Bam earthquake $(\mathrm{Mw}=6.5)$ (2003) in south of Iran, Silakhor earthquake $(\mathrm{Mw}=6.2)$ in west of Iran (2005) both with strike-slip responsible fault, as well as Saravan earthquake $(\mathrm{Mw}=7.5)$ in southeast of Iran (2013) with normal responsible fault. So, the strike-slip responsible fault for Tasuj earthquake can be the reason for the occurrence in small aftershokes.

In order to analyze the risk of aftershocks in this research and using data related to aftershocks of Tasuj earthquake, a method consisting of 3 parts has been presented. In the first part, the relationship between the depth and magnitude of aftershocks will be presented in order to reach a proper analysis of the risk of dangerous aftershocks. In the second part, the relationship between the magnitude of aftershocks and the time interval (seismic sequience) between their occurrence is analyzed in order to provide a relatively accurate presentation of the time of occurrence of the largest aftershock. In the third stage, the trend of changes in the number of aftershocks will be examined so that in case of reactivation of seismicity in the region, solutions can be provided to reduce the risk of aftershocks. To clarify the process presented in the relevant method, the flowchart discussed in this analysis is presented (Figure 6).

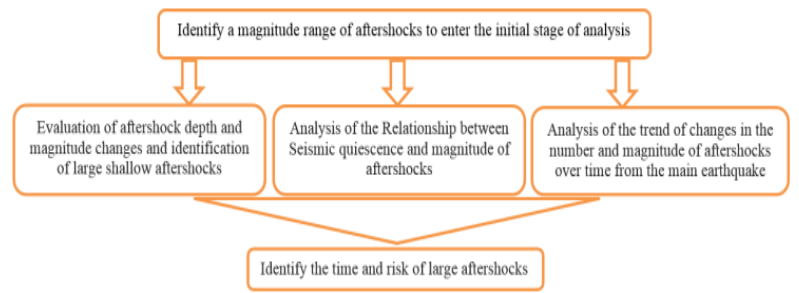

Figure 6. Flowchart of Risk analysis of aftershocks 
2-2-1-1 Step 1: Risk analysis of Depth and magnitude of aftershocks It is noteworthy that the detection of relationship between magnitude and focal depth of the larger aftershocks can highly contribute to risk management and identification of the possible the most dangerous aftershock. In this regard, approximate detection of the focal depth of large aftershocks provides a more efficient approach for risk evaluation in the early days after the main shock, as well as more accurate analysis of hazard level in the study area in terms of probable aftershocks. Evaluation of depth variation with a focus on large aftershocks $(M>3)$ indicates a unique pattern for these aftershocks and the focal depth of 8 aftershocks out of the first 9 aftershocks is limited to 4 to $8 \mathrm{~km}$. This indicates the presence of maximum stress $\left(\sigma_{2}\right.$, in strike-slip fault) in a certain direction and consistent with the focal depth of main shock (Table 3). This behavior, which was also reported for Silakhor plain earthquake (Saket, 2007) and Bam Earthquake (Saket and FatemiAghda, 2006), might be mainly related to the responsible fault for this type of main shock. For making a better comparison between magnitude and depth of aftershocks, the two parameters were normalized to inputs with a $0-1$ scale with division of primary data in each parameter to their largest value (Table 3 ). To normalize the data in a parameter, it is used to divide all its values into the largest available data. Accordingly, all data will be in the range between 0 and 1 . The first and latest rows of table 3 are contain aftershocks with the shallowest depth and greater magnitude $(M=4.1, M=3.9)$ and so this aftershocks are most dangerous aftershocks in Tasuj earthquake.

\begin{tabular}{|c|c|c|c|c|}
\hline Date & & & $\begin{array}{c}\text { Depth } \\
\text { normalized }\end{array}$ & $\begin{array}{l}\text { Magnitude } \\
\text { normalized }\end{array}$ \\
\hline $\begin{array}{c}\text { Time } \\
\text { (local) }\end{array}$ & Depin & Magnituae & & \\
\hline $\begin{array}{c}2013 / 04 / 18, \\
10: 44\end{array}$ & 12 & 4.1 & $12 / 18=0.667$ & $4.1 / 4.1=1.0$ \\
\hline $\begin{array}{c}2013 / 04 / 18 \\
10: 53\end{array}$ & 12 & 3 & $12 / 18=0.667$ & $3.0 / 4.1=0.73$ \\
\hline $\begin{array}{c}2013 / 04 / 18, \\
10: 58 \\
\end{array}$ & 18 & 3.3 & $18 / 18=1.0$ & $3.3 / 4.1=0.804$ \\
\hline $\begin{array}{c}\text { 2013/04/18, } \\
11: 01 \\
\end{array}$ & 12 & 3 & $12 / 18=0.667$ & $3.0 / 4.1=0.73$ \\
\hline $\begin{array}{c}\text { 2013/04/18, } \\
11: 08 \\
\end{array}$ & 14 & 3.1 & $14 / 18=0.778$ & $3.1 / 4.1=0.756$ \\
\hline $\begin{array}{c}\text { 2013/04/18, } \\
11: 09 \\
\end{array}$ & 15 & 3.2 & $15 / 18=0.833$ & $3.2 / 4.1=0.78$ \\
\hline $\begin{array}{c}2013 / 04 / 18, \\
11: 12 \\
\end{array}$ & 14 & 3.4 & $14 / 18=0.778$ & $3.4 / 4.1=0.83$ \\
\hline $\begin{array}{c}2013 / 04 / 18 \\
11: 20 \\
\end{array}$ & 16 & 3.8 & $16 / 18=0.889$ & $3.8 / 4.1=0.93$ \\
\hline $\begin{array}{c}\text { 2013/04/18, } \\
11: 39 \\
\end{array}$ & 12 & 3.9 & $12 / 18=0.667$ & $3.9 / 4.1=0.95$ \\
\hline
\end{tabular}

Table 3. Statistical parameters of main shock and aftershocks with $\mathrm{M} \geq 3$ of Tasuj Earthquake (IRSC)

This comparison shows that an inconsistency is observed between magnitude values and depth of aftershocks for some steps, where the increase in depth of aftershocks is associated with the increase in their magnitudes and vice versa, which can be applied for severe variations of magnitude values with the depth of aftershocks resulting in large aftershocks in the quakestricken areas. This conclusion can be used for risk management and the detection of occurrence time for aftershocks with higher risk. To determine the risk of the largest aftershock (eighth aftershock), a simple comparison between the magnitude and depth of the aftershock on the chart can be used to determine the risk of the largest aftershock based on depth. As shown in Figure 7, in the first and last data, the difference between the focal depth and magnitude of the aftershock is greater than the other data, and the focal depth is at its minimum and the magnitude is at its maximum among the aftershocks. It is recorded that these conditions show the highest risk of aftershocks. To determine the time of occurrence of the largest aftershock, we can use the change in magnitude and focal depth (Saket 2007). Thus, to predict large aftershocks in the Tasuj earthquake (the last aftershock presented in Figure 7, with a magnitude of 3.9) can be used by changing the magnitude behaviour and depth of aftershocks. As in the middle of the diagram in Figure 7, which is marked with a dashed line, the changes in magnitude and focal depth are in line, and immediately after that we see a change in the magnitude and depth of focus. In other words, with increasing and decreasing magnitude aftershocks, we do not face increasing and decreasing depth, respectively. This change in behaviour can indicate a change in stress in the activated fault zone and an increase in the probability of a large aftershock occurring. As shown in Figure 7, we see a large aftershock after these conditions.

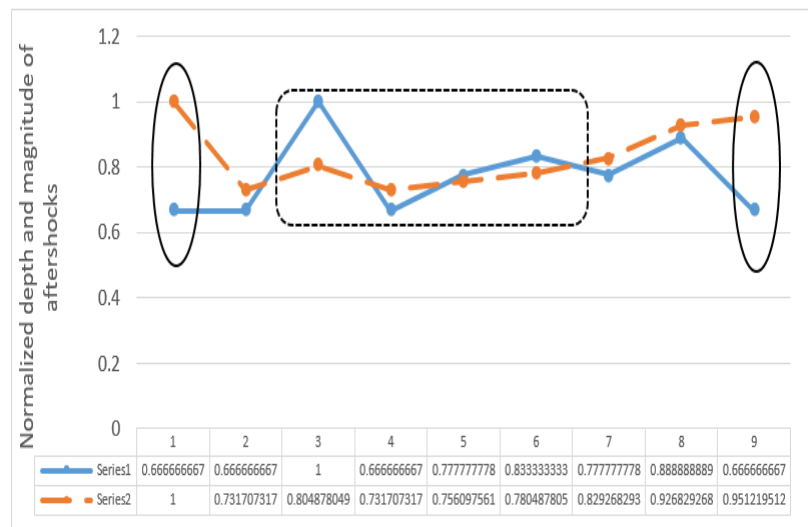

Figure 7. Variations in normalized magnitude and focal depth for aftershocks of Tasuj earthquake

2-2-1-2- Step 2: Analysis of the Relationship between Seismic quiescence and magnitude of aftershocks

For forecast the large aftershocks of this earthquake, we tested useful patterns that can also be used for other earthquakes. For this purpose, we recorded a certain quiescent time before large aftershocks followed by this earthquake that might result in stress accumulation for the occurrence of large aftershocks. This method has been used by other researchers in the world to forecast large aftershocks (Omi et al., 2013; Rosenberg and Jones, 1994; and Iwata, 2008). Table 4 presents aftershocks with $M \geq 3$ within one hour after the main shock. The third column of this table indicates the seismic quiescence between aftershocks. It is certain that an increase in the magnitude of aftershocks is followed by an increase in the seismic quiescence. This was done for the aftershocks with $M \geq 3$, except for the first aftershock that immediately occurred after the main shock with $\mathrm{Mb}=4.1$ that was affected of the concentration of high stress in the first few minutes after the main shock until the largest aftershocks $(M=3.9)$. Thus, this evidence can be used to forecast time interval of the selected aftershocks $(M \geq 3)$. It is noteworthy that aftershocks with a magnitude near to main shock can usually affect the quake-stricken areas. The correlation coefficient between these two parameters has been 
used to identify the relationship between these two parameters (the magnitude of the aftershocks and the seismic quiescence between them). According to the hypotheses presented in this paper and since the correlation between the two parameters is completely different in nature, if the correlation coefficient between these two parameters is above 0.5 , it indicates that there is a significant relationship between facial changes. There is a gap between these two parameters and the high correlation between these two parameters can be used as a scientific and appropriate method to identify the time of occurrence of large aftershocks.

In order to investigate the correlation between the two parameters mentioned in this section, data related to Tasuj earthquake aftershocks have been used. The correlation between the two parameters can be provided by the following formula:

$$
\mathrm{R}=\sum_{\mathrm{i}}\left(\mathrm{X}_{\mathrm{i}}-\mathrm{X}\right)\left(\mathrm{Y}_{\mathrm{i}}-\mathrm{Y}\right) /(\mathrm{n}-1) \mathrm{SxSy}
$$

Where $X, Y, S_{X}, S_{Y}$ are the sample means and standard deviations of $X i, Y i, i=1,2,3, \ldots$ and $\mathrm{n}$ is the sample size.

According to the proposed formula, the correlation coefficient of the two parameters of magnitude aftershocks and seismic sequience between them in the aftershocks of Tasuj earthquake is equal to 0.63 , which shows the direct and coordinated relationship between the two parameters and based on this we can It was concluded that by examining the time interval between the occurrence of aftershocks, we can find out the time of occurrence of the largest aftershock.

\begin{tabular}{|c|c|c|c|c|}
\hline Date, Time & Magnitude & $\begin{array}{c}\text { Seismic } \\
\text { Quiescence } \\
\text { (minute) }\end{array}$ & $\begin{array}{c}\text { Magnitude } \\
\text { Normalized }\end{array}$ & $\begin{array}{c}\text { Seismic } \\
\text { Quiescence } \\
\text { Normalized }\end{array}$ \\
\hline 2013/04/18, 10:53 & 3 & 9 & 0.769 & 0.473 \\
\hline $2013 / 04 / 18,10: 58$ & 3.3 & 5 & 0.846 & 0.263 \\
\hline $2013 / 04 / 18,11: 01$ & 3 & 3 & 0.769 & 0.157 \\
\hline $2013 / 04 / 18,11: 08$ & 3.1 & 7 & 0.794 & 0.368 \\
\hline $2013 / 04 / 18,11: 09$ & 3.2 & 1 & 0.820 & 0.052 \\
\hline $2013 / 04 / 18,11: 12$ & 3.4 & 3 & 0.871 & 0.157 \\
\hline $2013 / 04 / 18,11: 20$ & 3.8 & 8 & 0.974 & 0.421 \\
\hline $2013 / 04 / 18,11: 39$ & 3.9 & 19 & 1 & 1 \\
\hline
\end{tabular}

Table 4. Statistical parameters of aftershocks with $M \geq 3$ of Tasuj Earthquake (IRSC) and normalization of magnitude and seismic quiescence of aftershocks

2-2-1-3- Step 3: Analysis of the trend of changes in the number and magnitude of aftershocks

Another noteworthy feature of the aftershocks in the study area is their decreasing frequency within a certain period after the main shock, where this pattern is of a high order for some cases while being very irregular for some other earthquakes. Figure 8 illustrates the regular reducing pattern of the number of the aftershocks over time (days). This situation was observed in an irregular pattern for aftershocks of Goharan earthquake $\left(\mathrm{M}_{\mathrm{b}}=\right.$ 6.1, April 2013) in Hormozgan Province, Mourmoori earthquake ( $\mathrm{Mw}=6.2$, Agust 2013) in Ilam province and Kaki earthquake $\left(\mathrm{M}_{\mathrm{b}}=6.3\right.$, March 2013) in Bushehr Province in Iran. Such behaviour can be highly attributed to tectonic conditions of the study area, magnitude of the main shock, asperity of fault plan, geological conditions of the area, extension of the responsible fault and its relationship with neighbouring faults. These conditions can result in increased seismicity potential of that fault and consequently the stressed area, as well as surrounding faults (Shakib and Srivastuva, 2003). As shown in Figure 8, this condition was observed in the present study and a rather regular descending pattern was detected for aftershocks.

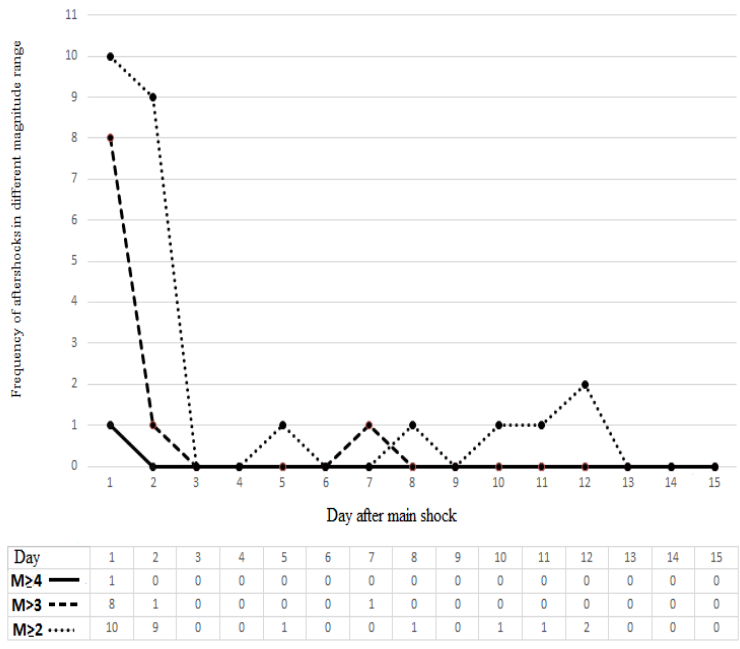

Figure 8 . The variation in the number of aftershocks within 14 days based on magnitude

- Evaluation of seismotectonic pattern of the study area and its segmentation to smaller units (using the foreshock patterns) allows for proposing suitable patterns to predict main earthquakes.

- The results of this work also show that the dip-slip focal mechanism proposed for Tasuj earthquake on map of major active faults of Iran is inconsistent with the strike-slip mechanism anticipated for the present earthquake. Because all other evidence shows that Tasuj fault is the cause of this earthquake, such mechanism should be modified in the mentioned map. Considering the inconsistency in the focal mechanism of the mentioned earthquakes, it is necessary to take the required steps for correcting these errors on the map of major active faults of Iran.

- The results of this research suggest that if the movement of small fault in a certain period of time is equal to a large fault, there is an expectation of medium and big earthquake on small fault. Because small fault cannot withstand the equivalent stress of large fault. This case can be as a precursor for time of moderate and big earthquake in seismic region.

- The monthly frequency of seismicity related to Tasuj fault and its neighbouring regions indicates a relative increase and then decrease within a $50 \mathrm{~km}$ radius around the epicentre of main shock. The first part is the increase in seismicity, which is due to the activation of the region and the formation of discontinuous cracks before the main earthquake, which manifests itself in the form of multiple foreshock. In the next step, which prepares the conditions for the occurrence of the 
main earthquake due to the relative joining of the cracks created along the fault plane due to micro-earthquakes, we will see the final resistance along the fault to move against the main earthquake that is faced with a decrease in the frequency of seismicity. This case can be used for presentation of suitable patterns of the prediction of main earthquakes based on foreshocks.

- The results of this work also suggest a usually uniform trend in variations of magnitude and depth of aftershocks, which can be help us for estimating the risk of aftershocks.

- Study of seismic quiescence was another important result in this research as an applied method used for risk reduction of the large aftershocks. This method presents time interval-based aftershocks and its role in forecasting their large types.

\section{References}

Bolt, B. A. (1990). Earthquakes, W. H. Freeman, and Company, New York, NY.

Cenni N., Viti M., Mantovani E., Bacchetti M. and Vannucchi A.(2015). Space geodetic data (GPS) and earthquake forecasting: examples from the Italian geodetic network. Bollettino di Geofisica Teorica ed Applicata Vol. 56, n. 2, pp. 129-150

Das, S., \& Henry, C. (2003). Spatial relation between main earthquake slip and its aftershock distribution. Reviews of Geophysics, 41(3), 10-13.

Djamour Y, Vernant P, Nankali H, Tavakoli F. (2011). NW Iran-eastern Turkey present-day kinematics: results from the Iranian permanent GPS network. Earth Planet. Sci. Lett. 307:27-34. Available from: http://dx.doi.org/10.1016/ j.eps1.2011.04.029

Gu, G and Meng G. (2011). Crustal movement in the earthquake area before and after 2008 Wenchuan earthquake as detected by precise single epoch positioning of GPS observations. Acta Seismoligica Sinika. Vol. 33, No. 3: 319-326.

Hessami, Kh, Jamali, F., \& Tabassi, H. (2003). Map of Major Active Faults of Iran. International Institute of Earthquake Engineering and Seismology Press, 1 sheet.

Iwata, T. (2008). Detection capability of global earthquakes after the occurrence of large earthquakes: Investigation of the Harvard CMT catalogue. Geophysical Journal International, 174(3), 849-856.

Karimzadeh S, Cakir Z, Osmanoglu B, Schmalzle G, Miyajima M, Amiraslanzadeh R, Djamour Y. (2013). Interseismicstrain accumulation across the North Tabriz Fault (NW Iran) deduced from InSAR time series. J. Geodynamics.66:53-58.
Mendoza, C., \& Hartzell, S. H. (1988). Aftershock patterns and main shock faulting. Bulletin of the Seismological Society of America, 78(4), 1438-1449.

Nishimura, T., Munekane, H., \&Yarai, H. (2011).The 2011 off the Pacific coast of Tohoku Earthquake and its aftershocks observed by GEONET. Earth, planets and space, 63(7), 631636.

NDRI. (2015). Report of large earthquake $(\mathrm{Mw}>5.0)$ in Iran. Department of applied studies and researches of natural disaster. Natural Disaster Institute of Iran.

Omi, T., Ogata, Y., Hirata, Y., \& Aihara, K. (2013). Forecasting large aftershocks within one day after the main shock. Scientific Report 3, 18 pp.

Omori, F. (1894). On the after-shocks of earthquakes, J. College Sci., Imp. Univ. Tokyo, 7, 111-200.

PourKermani M., \&Arian, M. (1999). Seismicity of Iran. Shahid Beheshti, University Press, 212 pp.

Richter, C. F. (1955). Foreshocks and aftershocks, in earthquakes in Kern County, California during 1952.California division of Mines, Bulletin 171, San Francisco, 177-197.

Reasenberg, P. A. \& Jones, L. M. (1994). Earthquake Aftershocks: Update. Science 265, 1251-1252.

Saket, A., \& FatemiAghda, S. M. (2009). Investigation of destructive and non-destructive aftershocks in important earthquakes. Engineering geology for tomorrow's cities, Geological Society, London, Engineering Geology Special Publication, (on CD-ROM insert, Paper 763).

Saket, A., FatemiAghda, S. M., \& Khadivi, Sh. (2005). A Comparison between Seismicity Parameters of Bam and Zarand Earthquakes with an Emphasis on their Aftershocks. $9^{\text {th }}$ conference of Iranian Geological Association, Kharazmi University, Tehran, Iran, 161169.

Saket, A. (2007). Seismicity Study of Silakhor Plain before and after Doroud Earthquake $\left(M_{L}=6\right.$, March 2006). $5^{\text {th }}$ conference of Engineering Geology and Environmental Geology of Iran. Kharazmi University, Tehran, Iran, 7 pp

Shaik, M.A., \& Srivastava, S. (2003). Statistical parameters of Bhuj earthquake sequence of January $26^{\text {th }}, 2001$. Journal of Earth System Science, 112(3), 397-400.

Tajima, F., \&Kanamori, H. (1985). Global survey of aftershock area expansion patterns. Physics of the Earth and planetary interiors, 40(2), 77-134.

Tartar, M., \&Farahbod, A. M. (2007). Study of 29 May 2004 Firouz Abad-Kojour Earthquake and its Aftershocks based on Analysis of Data Recorded in Local Seismometry Stations. Geosciences Scientific Quarterly Journal, 16(64), 24-37.

Tronin A.A. (2010). Satellite remote sensing in seismology. A review. Remote Sens., 2, 124-150, doi: 10.3390/ rs2010124. 
Zhao, B., Shi, Y., \& Gao, Y. (2011). Relation of aftershocks of the WenchuanMs 8.0 earthquake its implication to seismotectonics.Earth Science, (24), 107-113. 